\title{
OTIMIZAÇÃO DE SISTEMAS DE APROVEITAMENTO DE ÁGUA DE CHUVA PARA FINS DOMÉSTICOS EM ÁREAS RURAIS
}

\author{
OPTIMIZATION OF RAINWATER HARVESTING SYSTEMS FOR DOMESTIC \\ PURPOSES IN RURAL AREAS
}

\author{
Ana Caroline Bastos Lima de Souzaa, Juliana Farias Araújoa, \\ Anderson de Souza Matos Gadéa ${ }^{a}$, Eduardo Cohima \\ aUniversidade Estadual de Feira de Santana \\ anacarolinebxstos@gmail.com, julianafariaz1996@gmail.com, agadea@gmail.com, \\ edcohim@gmail.com
}

Submissão: 06 de março de 2021 Aceitação: 1 de julho de 2021

\section{Resumo}

Em virtude da importância do aproveitamento de água pluvial no Semiárido brasileiro, este artigo apresenta um método de otimização do dimensionamento de sistemas de captação e armazenamento de água de chuva (SCAC), além de um recurso simplificado de cálculo da área de captação e do volume ideal a partir de duas equações. A análise considerou as condições de atendimento de água da população rural baiana, e abrangeu dez cidades situadas em regiões específicas de homogeneidade pluviométrica. O procedimento consistiu na determinação de valores médios de Fração de Demanda (FD) e Fração de Reservação (FR) que fornecessem a combinação mais econômica de área de captação e volume de reservatório, capazes de atender a uma solicitação hídrica com pelo menos $95 \%$ de eficiência. Também se verificou uma forte relação positiva entre a demanda diária e as variáveis área e volume ótimos, sendo possível estimar esses valores por meio de equações que dependem apenas da demanda. Ao comparar os custos totais associados aos sistemas obtidos pelas frações médias e pelas equações com os custos totais ótimos de referência, foram encontrados para todos os municípios erros médios inferiores a 1,3\%, validando a metodologia desenvolvida. Por meio do Grau de Concentração da Precipitação, verificou-se a influência da distribuição temporal das chuvas no dimensionamento dos reservatórios, sendo que quanto mais concentrado for o regime pluviométrico, maior será o volume ótimo de armazenamento. Por fim, os autores recomendam a ampliação do número de municípios em trabalhos futuros, com o intuito de fornecer uma representação mais realista das condições de cada local.

Palavras-chave: captação e armazenamento de água de chuva; otimização; atendimento humano; áreas rurais.

\section{Abstract}

Due to the importance of rainwater utilization in the Brazilian Semiarid, this paper presents an optimal sizing method of rainwater harvesting systems (RWHS), in addition to a simplified resource that calculates the ideal catchment area and storage volume with only two equations. The analysis considered the water conditions of the rural population of Bahia, and covered ten cities located in specific regions of rainfall homogeneity. The procedure consisted of the determination of mean values of Demand Fraction (DF) and Reserve Fraction (RF) that provided the most economical combination of catchment area and reservoir volume, capable of meeting a water demand with at least $95 \%$ efficiency. There was also a strong positive relationship between daily demand and the optimal area and volume variables, making it possible to estimate these values usingequations that depend only on demand. When comparing the total costs associated with the systems obtained by the mean fractions and equations with the optimal total reference 
costs, average errors below $1,3 \%$ were found forall municipalities, validating the methodology developed. Through the Degree of Precipitation Concentration, it was verified the influence of the temporal distribution of rainfall on the dimensioning of the reservoirs, where the more concentrated the rainfall regime, the greater the optimum volume of storage. Finally, the authors recommend expanding the number of municipalities in future studies, in order to provide a more realistic representation of the conditions in each location.

Keywords: rainwater harvesting system; optimization; human supply; rural areas.

\section{INTRODUÇÃO}

A região Semiárida Brasileira é composta por 1.262 municípios que ocupam $12 \%$ do território nacional (1,03 milhões de km²) (BRASIL, 2017). Marcada por frequentes eventos de seca, essa região é caracterizada por precipitação pluviométrica média anual inferior ou igual a 800 $\mathrm{mm}$ e índice de evaporação em torno de 3.000 $\mathrm{mm}$ por ano (ASA, 2021a; IBGE, 2017). Esse deficit hídrico é ainda mais desafiador por conta da distribuição irregular da precipitação no tempo e pela predominância de solos pouco desenvolvidos com baixa capacidade de infiltração, os quais contribuem para que os recursos hídricos subterrâneos sejam escassos (ARAÚJO, 2011; COSTA; SILVEIRA, 2017). Estima-se que mais de $90 \%$ da precipitação não seja aproveitada por conta da sua evaporação e do seu escoamento superficial (ASA, 2021a).

Os aspectos naturais são agravados por medidas públicas emergenciais ineficazes, como a construção de grandes açudes e poços que, por muitos anos, promoveram a concentração irregular da água de qualidade e privilegiaram uma minoria latifundiária. Essa questão está fortemente ligada a uma distribuição desigual de terras e privou grande parte da população do atendimento às suas necessidades básicas (ASA, 2021b).

A precariedade do acesso à água em comunidades rurais difusas perpassa as esferas política e social, as quais potencializam a condição de vulnerabilidade da população mais pobre, historicamente marginalizada. Lemos (2020) demonstrou em sua pesquisa o impacto da ausência de políticas públicas efetivas nos atuais níveis de qualidade de vida das famílias do semiárido brasileiro, constituindo privações de renda, educação e saneamento. Nesse sentido, alternativas que possibilitem 0 acesso descentralizado e democrático da água tornam-se cada vez mais relevantes, como o aproveitamento da água de chuva.

O uso de reservatórios para estocar água em tempos chuvosos é bastante antigo, sendo até hoje difundido em diversos lugares do mundo. A Índia, Japão, Austrália, Estados Unidos são alguns dos países que têm adotado o aproveitamento da água de chuva como uma das medidas predominantes na conservação de água, de modo que em alguns estados é considerado como prática obrigatória para edifícios. $\mathrm{Na}$ Tailândia, dentre as fontes disponíveis, esta técnica garante o acesso à água a $40 \%$ da população. Países como China, Argentina e Brasil também utilizam esse sistema para criação de gado, irrigação em pequena escala e recuperação do lençol freático (PALA et al., 2021). O Programa Mundial de Avaliação da Água considera a água de chuva como fonte melhorada para abastecimento doméstico de água (WWAP, 2009), enquanto a OMS, na quarta edição das Diretrizes para Qualidade da Água Potável (Guidelines for Drinking Water Quality), considera que sistemas de aproveitamento de água de chuva bem operados e complementados por boas práticas de higiene constituem uma fonte de água potável de baixo risco (WHO, 2011). Na esfera nacional, o Plano Nacional de Recursos Hídricos aponta a água de chuva como recurso a ser usado em substituição ou suplementação de fontes tradicionais (BRASIL, 2006), e o Congresso alterou a Lei 9433/97 para estabelecer a água de chuva como parte do sistema de gerenciamento para uso humano (BRASIL, 1997).

Fundamental para o abastecimento humano em períodos de escassez hídrica, essa tecnologia ganhou destaque no Brasil com o programa Um Milhão de Cisternas Rurais (P1MC), que, desde o seu início em 2003 até fevereiro de 2021, proporcionou a construção de 628.355 cisternas de placa nas áreas rurais da região semiárida. Sua aplicação contou com a participação das famílias beneficiadas e trouxe importantes avanços às comunidades, como o aumento da frequência escolar, diminuição da incidência de doenças associadas à ingestão de água contaminada e redução da sobrecarga de trabalho doméstico das mulheres (ASA, 2021a). 
Diante das transformações provocadas por essa iniciativa e da demanda social ainda não atendida, foi implementada, em 2011, outra política pública de acesso hídrico, o Água Para Todos (APT). Neste caso, além da captação de água para consumo humano, recorreu-se a soluções tecnológicas que possibilitam a produção de alimentos e criação de animais como elementos fundamentais para a garantia da segurança alimentar e nutricional (RUEDIGER, $M$. A., 2018).

Os programas P1MC e APT disseminaram cisternas com volume padrão de $16 \mathrm{~m}^{3}$. No entanto, estudos comprovam que a padronização nos volumes de reservatório e/ou área de captação tende a diminuir a eficiência dos sistemas, pois não considera o regime pluviométrico local, o número de usuários e a área de captação disponível (ARAUJO; COHIM, 2016; ANDRADE NETO, 2013; CAMPISANO; MODICA, 2012; COHIM; ORRICO, 2015; GHISI, 2010).

A problemática da uniformização dos volumes tem consequências tanto em termos quantitativos, quanto qualitativos. No caso do P1MC, por exemplo, Santos, Ceballos e Sousa (2013) apontaram, em uma pesquisa conduzida no interior da Paraíba, que a incompatibilidade entre o volume armazenado e as demandas hídricas levou ao uso de carros-pipas para suprir as necessidades das famílias. Essa fonte secundária não possui garantia de qualidade e compromete o consumo da água, de modo que em um estudo feito por Morais (2016), para comunidades rurais sergipanas, foi verificada, inclusive, a presença de coliformes totais na mistura de água de chuva com água de carrospipas. Portanto, o dimensionamento adequado dos sistemas de captação e armazenamento de água pluvial é fundamental para otimizar sua operação, uma vez que o subdimensionamento resulta em sistemas incapazes de fornecer uma fonte de água suficiente e confiável, enquanto que o superdimensionamento aumenta os custos de capital incorridos com benefícios limitados (SEMAAN et al., 2020).

Algumas pesquisas são voltadas ao dimensionamento e otimização dos sistemas de captação e armazenamento de água de chuva (SCAC), principalmente em relação aos reservatórios, como os componentes individuais mais caros desses sistemas e que correspondem a cerca de $30 \%$ dos custos, incluindo a construção e operação do sistema (GURUNG; SHARMA; UMAPATHI, 2012). Dentre as variáveis mais utilizadas no processo de otimização de tais sistemas, o custo aparece com maior frequência, sendo que a abordagem mais comum avalia 0 custo de água do tratamento centralizado que seria deslocado por conta do uso da água de chuva (SEMAAN et al., 2020). No entanto, essa técnica não é adequada para a população que não é atendida pelas redes de abastecimento de água, sendo que, no estado da Bahia, corresponde a $46 \%$ da população rural (SNIS, 2018).

Assim, uma análise que relacione a eficiência de atendimento à demanda com um SCAC ótimo seria mais recomendada para as regiões semiáridas baianas que não são atendidas pelas redes de abastecimento de água. Diante disso, este trabalho propõe uma metodologia de dimensionamento otimizado de sistemas de aproveitamento de água da chuva para fins domésticos, incluindo uma abordagem integrada do sistema, que considera o volume do reservatório e área de captação, de maneira que possibilite o maior retorno econômico e social para os investimentos na infraestrutura hídrica da região. A partir de dois parâmetros adimensionais ou de duas equações lineares, é possível determinar as dimensões ideais para a área de captação e o reservatório do sistema.

\section{METODOLOGIA}

Este estudo adotou o seguinte delineamento: 1) Seleção dos municípios a partir do zoneamento pluviométrico da Bahia, 2) Estudo de caso para o desenvolvimento do modelo de otimização, tendo como foco a cidade de Ibotirama-BA, 3) Reprodução do procedimento para as dez localidades por meio de um programa computacional, 4) Análise do Grau de Concentração da Precipitação e 5) Análise de sensibilidade do custo total.

A metodologia proposta se baseia na técnica de otimização econômica de sistemas de captação de água de chuva apresentada por Giffoni e Cohim (2019), a qual determina o cenário de menor custo entre diferentes combinações de área de captação e volume de reservatório capazes de atender a uma dada demanda. 


\section{1 Área de estudo}

O estado da Bahia é formado por 417 municípios distribuídos ao longo de uma área de aproximadamente $565 \mathrm{~km}^{2}$ (IBGE, 2020). Essa extensão territorial é marcada por diferentes condições climáticas, predominando o clima tropical, com médias de temperaturas elevadas e máximas acima de $30^{\circ} \mathrm{C}$. As regiões centro e norte, de clima semiárido, enfrentam longos períodos de estiagem, enquanto que pontos isolados no centro do estado, em áreas de maior altitude, e chapadas no extremo oeste apresentam uma sazonalidade bem definida e clima muito úmido (SANTOS et al., 2013).

A Bahia também apresenta uma alta variabilidade espacial da pluviosidade, em que os índices pluviométricos anuais das faixas litorâneas são regulares e superiores a $1100 \mathrm{~mm}$, chegando até mesmo a $2000 \mathrm{~mm}$ em algumas áreas. Por outro lado, as faixas semiáridas (localizadas nas regiões norte, nordeste e uma pequena porção no centro-sul) podem apresentar índices em torno de $500 \mathrm{~mm}$, distribuídos de forma irregular (DINIZ, 2012).

\subsection{Seleção dos municípios e dados pluviométricos}

Com a finalidade de retratar a alta variabilidade espacial e temporal das precipitações na Bahia, este estudo abrange as regiões específicas de homogeneidade pluviométrica definidas a partir do zoneamento proposto por Simões, Cohim e Araújo (2018). Esses autores levaram em consideração a precipitação anual, a proximidade entre os postos e a distribuição espacial e temporal das chuvas.

Nesse sentido, são estudados 10 postos pluviométricos, os quais representam municípios localizados em cada região específica, a saber: Aratuípe, Itaguaçu da Bahia, Angical, Alcobaça, Miguel Calmon, Cândido Sales, Planalto, Ibotirama, Queimadas e Rafael Jambeiro. A distribuição dos postos ao longo do estado da Bahia pode ser observada na Figura 1, em que estão destacados por pontos vermelhos, e na Tabela 1, na qual são mostradas suas coordenadas geográficas.

As séries diárias de precipitação - com 33 anos de observações - foram coletadas em postos pluviométricos distribuídos espacialmente no estado baiano, e encontram-se disponíveis no
Portal HidroWeb, da Agência Nacional de Águas (ANA), e no Banco de Dados de Recursos Hídricos (BDRH), do Instituto do Meio Ambiente e Recursos Hídricos da Bahia (Inema).

\subsection{Estudo de caso}

A cidade de lbotirama faz parte da Zona Pluviométrica Homogênea de número 8, conforme apresentada na Tabela 1, e está localizada no oeste do estado da Bahia, mais precisamente, na bacia do Médio São Francisco, caracterizada pelos climas seco, subúmido e semiárido. Inserido na zona do Polígono das Secas, o município está sujeito a longos períodos de estiagem, tornando essencial a implantação de tecnologias sociais para captação e armazenamento de água de chuva (BRASIL, 2010).

Inicialmente, foram definidos o método de dimensionamento de reservatório a ser utilizado e os parâmetros necessários à sua aplicação. A partir de uma eficiência mínima de atendimento e de valores específicos de demanda, foram calculados os volumes associados a diferentes áreas de captação. Em seguida, levando em consideração o critério de menor custo total, foi escolhida uma combinação de área e volume para cada demanda diária. Ao determinar a Fração de Demanda e de Reservação de cada combinação, observou-se uma proximidade entre as frações ótimas das diferentes demandas. Essa semelhança chamou a atenção para a possibilidade de se utilizar frações médias que fossem capazes de fornecer os valores ótimos de área e volume associados a qualquer demanda. Portanto, neste estudo de caso, verifica-se a viabilidade dessa alternativa, que tornaria o processo de dimensionamento do sistema de aproveitamento de água pluvial mais rápido e direto.

\subsubsection{Caracterização de parâmetros}

A definição do método de dimensionamento do reservatório determina quais informações são necessárias ao cálculo de seu volume. Neste caso, é utilizado um modelo comportamental, o qual permite a simulação da operação do reservatório em um período de tempo específico. Sendo assim, foram necessários a área de captação, os índices pluviométricos, o número de moradores, a demanda per capita diária e a 
eficiência de atendimento desejada.

Figura 1: Distribuição espacial dos postos com base no zoneamento pluviométrico considerado

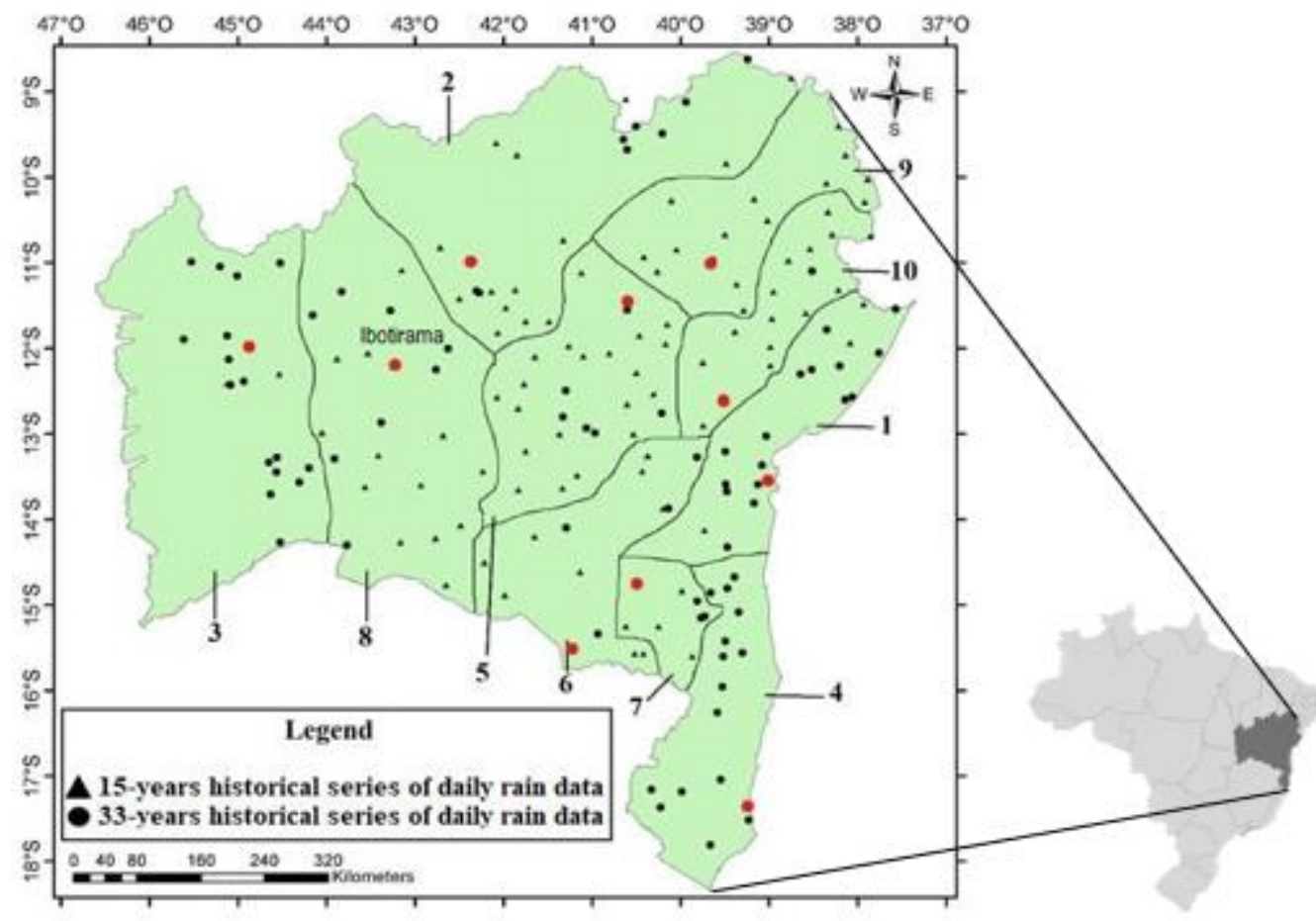

Fonte: Adaptada de Simões, Cohim e Araújo (2018).

*Legenda

Triângulo: Série histórica de dados de precipitação diária de 15 anos

Círculo: Série histórica de dados de precipitação diária de 33 anos

*Escala do mapa em quilômetros

Tabela 1: Localização dos postos estudados

\begin{tabular}{ccccc}
\hline Região & Município & $\begin{array}{c}\text { Código } \\
\text { do posto }\end{array}$ & $\begin{array}{c}\text { Latitude / (graus } \\
\text { e décimos) }\end{array}$ & $\begin{array}{c}\text { Longitude / (graus } \\
\text { e décimos) }\end{array}$ \\
\hline 1 & Aratuípe & 1339020 & $-13,567$ & $-39,002$ \\
2 & Itaguaçu da Bahia & 1042012 & $-10,986$ & $-42,342$ \\
3 & Angical & 1144014 & $-11,979$ & $-44,877$ \\
4 & Alcobaça & 1739010 & $-17,515$ & $-39,227$ \\
5 & Miguel Calmon & 1140000 & $-11,432$ & $-40,604$ \\
6 & Cândido Sales & 1541001 & $-15,505$ & $-41,229$ \\
7 & Planalto & 1440009 & $-14,744$ & $-40,492$ \\
8 & Ibotirama & 1243011 & $-12,1806$ & $-43,223$ \\
9 & Queimadas & 1039019 & $-10,974$ & $-39,633$ \\
10 & Rafael Jambeiro & 1239007 & $-12,585$ & $-39,518$ \\
\hline
\end{tabular}

Fonte: ANA (2021).

Foi adotado um total de quatro (4) pessoas por domicílio, que é o valor médio para 0 ambiente rural baiano calculado a partir do Censo
Demográfico de 2010 (IBGE, 2010. A fim de simular cenários com baixo e alto consumo de água, considerou-se demandas per capita diárias 
de: 15, 30, 45, 60, 75 e 90 L. Quanto à área de captação, estabeleceu-se um valor mínimo de 20 $\mathrm{m}^{2}$, que variava sob incrementos de $5 \mathrm{~m}^{2}$ até que uma eficiência de atendimento específica fosse atendida.

Como este trabalho é voltado para áreas rurais que não são atendidas pelas redes de abastecimento de água, tomou-se 95\% como valor mínimo de eficiência de atendimento, entendido aqui como o percentual da demanda no período simulado que poderia ser atendido com água de chuva.

\subsubsection{Aplicação do modelo comportamental}

O modelo comportamental empregado se baseia em um balanço hídrico de intervalo diário (FEWKES, 2000), constituído pelas Equações 1, 2,3 e 4.

$Q_{[(t)}=P_{[(t)} \times A \times C$

$\mathrm{Y}_{(\mathrm{t})}=\min \left\{\begin{array}{c}\mathrm{D}_{(\mathrm{t})} \\ V_{(\mathrm{t}-\mathrm{t})}+\theta \mathrm{Q}_{(\mathrm{t})}\end{array}\right.$

$V_{(t)}=\min \left\{\begin{array}{c}\left(V_{(t-1)}+Q_{[(t)}-\theta Y_{(t)}\right)-(1-\theta) Y_{[(t)} \\ R-(1-\theta) Y_{[(t)}\end{array}\right.$

Em que, ${ }^{Q_{(\mathrm{t})}}$ se refere à quantidade de água, em litros, que escoa para o reservatório no intervalo de tempo $t$ (dia); ${ }^{P_{[t]}}$ corresponde à precipitação nesse mesmo período $(\mathrm{mm})$; A é a área de captação $\left(m^{2}\right)$; e C é o coeficiente de escoamento superficial (Runoff), que neste caso equivale a 0,8 . Nas equações 2 e 3 , pode-se notar a presença do coeficiente adimensional ${ }^{\theta}$, que, por sua vez, varia de 0 a 1 . Adota-se ${ }^{\theta=0}$ quando a demanda diária é totalmente consumida antes que o escoamento de água de chuva naquele período seja adicionado ao tanque, $e^{\theta=1}$ quando o consumo é feito posteriormente. Foi utilizado $\theta=0,5$, com o intuito de abordar uma situação intermediária. Quanto às outras variáveis, $D_{[t]}$ refere-se à demanda diária total, em litros, no período ${ }^{t}$; $Y_{\text {(t) }}$ é o volume de água, em litros, utilizado para suprir a demanda naquele período; $V_{\text {[t] }}$ é o volume, em litros, armazenado no reservatório no mesmo período; e $\mathrm{R}$ é a capacidade do reservatório, em litros.
A eficiência de atendimento $\left(E_{A}\right)$ foi verificada pela Equação 4.

$E_{A}(\%)=\frac{2 Y_{(t)}}{\sum D} \times 100$

Em que, $\Sigma D$ e ${ }^{\sum Y_{(t)}}$ correspondem ao somatório da quantidade de água demandada e ao volume utilizado, respectivamente, durante $o$ período estudado.

O procedimento consistiu, portanto, na obtenção de volumes que suprissem a quantidade de água solicitada, considerando o valor mínimo de eficiência e diferentes áreas de captação, as quais sofriam incrementos de $5 \mathrm{~m}^{2}$. Para cada demanda, foram geradas combinações de área de captação e volume de reservatório.

\subsubsection{Fração de Demanda e Fração de Reservação}

Levando em consideração a variedade de parâmetros utilizados nesse método, julgou-se necessário normalizar essas combinações de valores através de fatores adimensionais. Para isso, utilizou-se a ideia proposta por Fewkes (2000) e calculou-se a Fração de Demanda $\left(F_{D}\right)$ e a Fração de Reservação $\left(\mathrm{F}_{\mathrm{R}}\right)$. Esses parâmetros são obtidos pelas Equações 5 e 6 .

$$
\begin{aligned}
& F_{D}=\frac{D}{A \times P} \\
& F_{R}=\frac{V}{A \times P}
\end{aligned}
$$

Em que, $D$ corresponde à demanda anual (L); V é o volume do reservatório (L); A refere-se à área de captação $\left(m^{2}\right)$; e $P$ é a precipitação média anual $(\mathrm{mm})$.

\subsubsection{Definição do ponto ótimo e das frações médias}

A concepção do SCAC se baseou na cartilha publicada pelo Centro de Desenvolvimento Agroecológico Sabiá (SANTOS; MEDEIROS; ANGOLA, 2013), em que se utiliza uma Cisterna Telhadão como tecnologia de aproveitamento de água de chuva. Neste sistema, a água é captada por um telhado em forma de galpão e encaminhada por meio de calhas e tubos a uma cisterna de placas de concreto. A estrutura de 
captação se destaca por também possibilitar outros usos, como estocagem de alimentos, criação de animais e armazenamento de ferramentas de trabalho. Foi considerado um telhado constituído por telhas de fibrocimento onduladas com inclinação de 10\%, apoiadas em estrutura de madeira e pilares de alvenaria de seção $20 \times 20 \mathrm{~cm}$, com espaçamento máximo de 3 m. Para a conexão com a cisterna, foi prevista uma calha de chapa de aço galvanizado e tubulação de PVC. A coleta de água será feita com uma bomba de repuxo manual, pois não se considerou a existência de um reservatório superior.

O orçamento das partes de captação e de armazenamento foi realizado a partir do banco de dados do Sistema Nacional de Pesquisa de Custos e Índices da Construção Civil (SINAPI, 2021), atualizado para janeiro de 2021, e do Sistema de Orçamento de Obras de Sergipe (ORSE, 2021), atualizado para dezembro de 2020. Foram feitas composições de custo para a construção de cisternas com volume variando de 5 a $100 \mathrm{~m}^{3}$ e de telhados com área variando de 50 a $300 \mathrm{~m}^{2}$. As despesas relacionadas à contratação de mão de obra, como armador, pedreiro e servente, foram contabilizadas, porém, não se considerou a manutenção do sistema.

Diante disso, foi possível interpolar os resultados e obter funções que permitem calcular o custo associado ao telhado e ao reservatório em diferentes cenários. Os valores de área de captação e volume de armazenamento encontrados para cada uma das demandas analisadas foram substituídos nessas equações, obtendo-se, no final, um custo total para cada combinação. O ponto ótimo corresponde à combinação mais econômica, ou seja, aquela cujo custo total seja o menor.

\subsection{Reprodução do procedimento para as dez localidades por meio de um programa computacional}

Ao finalizar o estudo de caso em Ibotirama, desenvolveu-se um programa computacional no software Matlab, que realiza o procedimento para todas as cidades de uma forma mais rápida e precisa. O volume mínimo de armazenamento adotado foi de 2500 L, o qual variava em intervalos de 100 L. As áreas de captação mínima e máxima correspondem a 20 e $400 \mathrm{~m}^{2}$, respectivamente, com taxa de variação de $5 \mathrm{~m}^{2}$.
Em relação às demandas diárias, foi considerado o intervalo de 60 a $360 \mathrm{~L}$ e incrementos de $15 \mathrm{~L}$, os quais, neste caso, foram feitos sobre os valores de demanda diária total e não per capita. As equações de custo da cobertura e do reservatório foram mantidas, assim como o valor de eficiência mínima de atendimento.

\subsection{Análise do Grau de Concentração da Precipitação (GCP)}

Este estudo também buscou analisar a influência da distribuição temporal das chuvas nas Frações de Demanda e Reservação e, consequentemente, no dimensionamento do sistema de captação e armazenamento. Para isso, foram utilizados os valores de GCP de cada posto pluviométrico, encontrados por Simões, Cohim e Araújo (2018). Essa grandeza considera as precipitações mensais como grandezas vetoriais, orientadas em um círculo trigonométrico, cuja direção de cada vetor depende do mês de ocorrência. Sendo assim, cada um dos 12 meses assume um ângulo de $30^{\circ}$. O valor do GCP varia de 0 a 1 , de modo que chuvas mais distribuídas ao longo do ano resultam em valores próximos de 0 , e chuvas mais concentradas originam valores próximos de 1. Seu cálculo é feito a partir das Equações 7, 8, 9 e 10 (Ll et al., 2011).

$$
\begin{aligned}
& \mathrm{R}_{\mathrm{i}}=\sum \mathrm{r}_{\mathrm{ij}} \\
& R_{x \mathrm{i}}=\sum r_{\mathrm{i} j} \cdot \sin \theta_{\mathrm{ij}} \\
& R_{y i}=\sum r_{\mathrm{i} j} \cdot \cos \theta_{\mathrm{i} j} \\
& \mathrm{GCP}=\frac{\sqrt{\mathrm{R}_{\mathrm{xi}}{ }^{2}+\mathrm{R}_{\mathrm{yi}}{ }^{2}}}{\mathrm{R}_{\mathrm{i}}}
\end{aligned}
$$

Em que, $R_{i}$ corresponde à precipitação anual, e $R_{x i}$ e $R_{y i}$ às componentes " $x$ " e " $y$ " desse vetor; $r_{i j}$ se refere à precipitação mensal, onde i e j indicam o ano e o mês, respectivamente; e $\theta_{\mathrm{ij}}$ representa o ângulo desse mês em estudo.

\subsection{Análise de sensibilidade do custo total}

Com o intuito de apurar o efeito da variação de preço do reservatório e do telhado no custo 
total e, consequentemente, a determinação do ponto ótimo, recorreu-se a uma análise de sensibilidade. Foram considerados incrementos de $25 \%$ e $50 \%$ sobre os valores de cada um dos dois componentes do sistema. Inicialmente, fixouse a função de custo do reservatório e variou-se a função de custo da área de captação. Em seguida, foi fixada a função de custo da área de captação e variada a função de custo do reservatório. Esse procedimento foi realizado para duas cidades, especificamente Rafael Jambeiro e Itaguaçu da Bahia, considerando-se demandas diárias de 60,120, 180, 240, 300 e $360 \mathrm{~L}$.

\section{RESULTADOS, ANÁLISE E DISCUSSÃO}

\subsection{Estudo de caso}

As Figuras 2a e 2b apresentam as curvas de custo de cada componente do sistema de aproveitamento de água de chuva, em que o custo de execução da área de captação possui caráter linear e o custo associado à construção do reservatório apresenta um comportamento exponencial. Estudos como o de Lani et al. (2018) incluem custos contínuos de operação de bombas elétricas e custos com água potável que são poupados pelo uso do SCAC. No entanto, este trabalho admite a água de chuva como fonte única e leva em consideração o bombeamento manual realizado pelos próprios moradores, dispensando a inserção dessas outras variáveis.

As funções de custo foram utilizadas no cálculo do custo total de cada combinação de área de captação e volume de reservatório e, consequentemente, na determinação do ponto ótimo. Isso pode ser visualizado na Tabela 2 e Figura 3, as quais consideram uma demanda diária de 120 L. Em ambas, o aumento da cobertura provoca a redução do volume da cisterna, o que acaba refletindo nos seus respectivos custos e gerando um ponto mínimo no custo total. Todas as combinações apresentadas atendem à eficiência mínima adotada de $95 \%$, no entanto, uma promove maior economia. Neste caso, o sistema mais econômico é aquele destacado, com custo total equivalente a $R \$ 14.640,00$, área de captação de $80 \mathrm{~m}^{2}$, reservatório de $26,9 \mathrm{~m}^{3}$ e valores de Fração de Demanda e de Reservação iguais a, respectivamente, 0,757 e 0,466.

Uma área de captação de $75 \mathrm{~m}^{2}$ (Tabela 2) corresponde ao menor valor de área, cujo volume de armazenamento associado é capaz de suprir a demanda com 95\% de eficiência. Áreas de captação menores que isso exigiriam reservatórios de dimensões elevadas e, ainda assim, não alcançariam 0 potencial de atendimento especificado.

\section{Figura 2: Custo associado à construção da área de captação (a) e custo associado à construção do reservatório (b)}

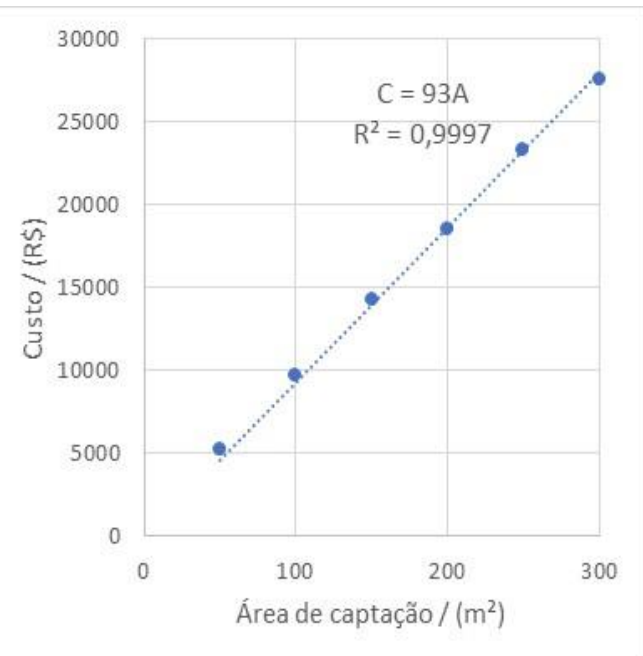

(a)

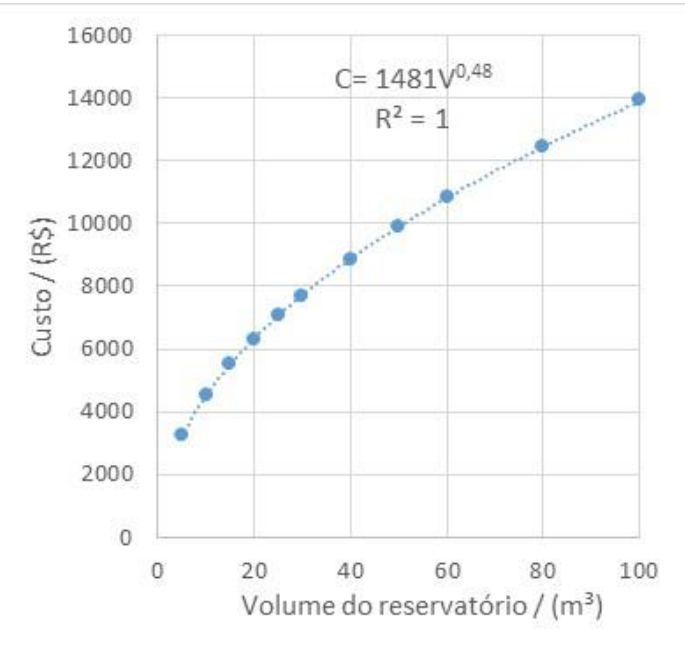

(b)

Fonte: Os autores (2021).

*Data de elaboração de custos: 11/03/2021

Taxa de câmbio comercial nesta data: R\$ 5,5884/US\$ (IPEA, 2021) 
Tabela 2: Determinação do ponto ótimo (realçado em cinza) para demanda diária de $120 \mathrm{~L}$ na cidade de lbotirama-BA

\begin{tabular}{|c|c|c|c|c|c|c|}
\hline $\begin{array}{c}\text { Área / } \\
\left(m^{2}\right)\end{array}$ & $\begin{array}{l}\text { Volume / } \\
\qquad\left(\mathrm{m}^{3}\right)\end{array}$ & $\begin{array}{l}\text { Custo da área } \\
\text { / (R\$1000) }\end{array}$ & $\begin{array}{c}\text { Custo do reserv. } \\
\text { / ( } \mathbf{R} \$ 1000)\end{array}$ & $\begin{array}{l}\text { Custo Total / } \\
\text { (R\$1000) }\end{array}$ & $\mathrm{F}_{\mathrm{R}}$ & $\mathrm{F}_{\mathrm{D}}$ \\
\hline 75 & 33,4 & 6,98 & 7,98 & 14,95 & 0,616 & 0,807 \\
\hline 80 & 26,9 & 7,44 & 7,20 & 14,64 & 0,466 & 0,757 \\
\hline 85 & 24,5 & 7,91 & 6,87 & 14,78 & 0,398 & 0,712 \\
\hline 90 & 23,0 & 8,37 & 6,67 & 15,04 & 0,354 & 0,673 \\
\hline 95 & 22,2 & 8,84 & 6,56 & 15,39 & 0,323 & 0,637 \\
\hline 100 & 21,6 & 9,30 & 6,48 & 15,78 & 0,299 & 0,605 \\
\hline 105 & 21,3 & 9,77 & 6,42 & 16,19 & 0,280 & 0,577 \\
\hline 110 & 21,1 & 10,23 & 6,39 & 16,62 & 0,265 & 0,550 \\
\hline
\end{tabular}

Fonte: Os autores (2021).

Figura 3: Gráfico de custos em função da área de captação para demanda diária de $120 \mathrm{~L}$ na cidade de lbotirama-BA

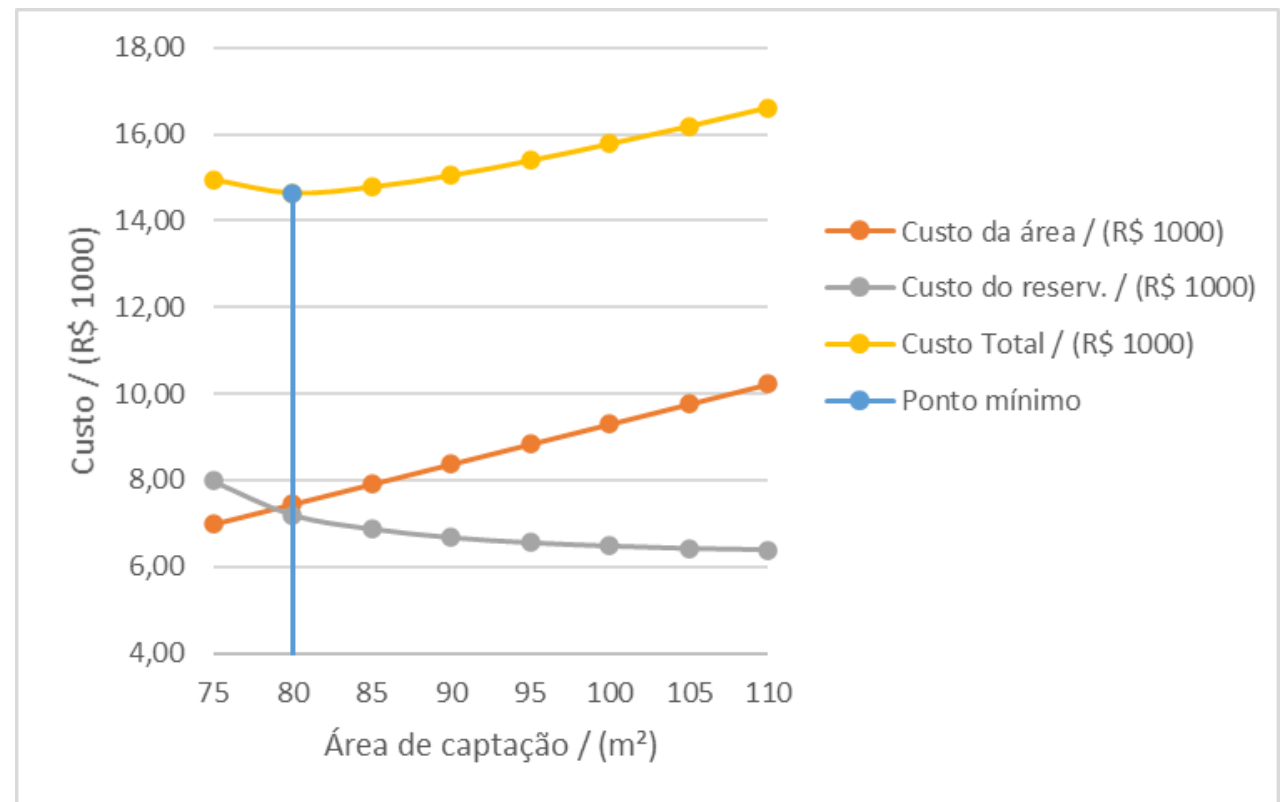

Fonte: Os autores (2021).

Para os locais em que já exista uma residência, a cobertura da mesma pode ser aproveitada como área de captação. Se a cobertura for menor que a área ótima, demonstrase a utilização do reservatório com volume ótimo e a construção de uma área adicional. Usando Ibotirama como referência, demanda diária de $120 \mathrm{~L}$ e uma moradia de $75 \mathrm{~m}^{2}$ de área de captação, por exemplo, o custo total seria decorrente da despesa associada aos $5 \mathrm{~m}^{2}$ de ampliação, ou seja, de $R \$ 465,00$, e da execução do reservatório de $26,9 \mathrm{~m}^{3}$, levando a um somatório de cerca de $R \$ 7.665,00$. É mais econômico adotar esse procedimento do que manter a cobertura inicial e investir em um reservatório maior, de custo equivalente a $R \$$ $7.980,00$, como exibido na primeira linha da Tabela 2.

As simulações para demandas de 60 a $360 \mathrm{~L}$ revelaram que os valores de $F D$ e de FR associados à combinação ótima de cada demanda tinham pouca variação, justificando-se a 
análise da possibilidade de se usar valores médios para esses parâmetros, o que traria uma maior simplicidade nos cálculos para casos diversos na área de influência do posto pluviométrico. Desse modo, foram calculados FD e FR médios que, ao serem substituídos nas Equações 5 e 6, forneceram novos valores de área de captação e volume de armazenamento para cada demanda. Os custos totais das novas combinações foram determinados e comparados àqueles associados aos valores reais, como exposto na Tabela 3. Pelo fato de estarem relacionados às frações médias, esses parâmetros foram identificados como: $A_{F M}$, para a área de captação; $V_{F M}$, para o volume do reservatório; e Custo Total $\mathrm{FM}_{\mathrm{FM}}$, para o custo total do sistema.

Os erros entre os custos totais reais e os custos totais obtidos pela aplicação de FD e FR médios correspondem a menos de $1 \%$, sendo possível, assim, utilizar os valores FD médio = 0,763 e FR médio $=0,479$ para realizar 0 dimensionamento otimizado do sistema localizado em Ibotirama de uma forma mais prática e direta. Ao invés de recorrer às equações do modelo comportamental, uma série histórica de precipitação e diferentes combinações de área e volume, só é necessário conhecer a precipitação anual média, a demanda familiar e, por fim, aplicar as Frações de Demanda e de Reservação nas suas equações de origem.

Por exemplo, para atender uma demanda de $120 \mathrm{~L}$ em Ibotirama, o procedimento se resumiria a calcular, inicialmente, a razão entre a demanda anual e o produto de FD médio e a precipitação média anual $(723,4 \mathrm{~mm})$, o que fornece uma área ótima de 79,4 $\mathrm{m}^{2}$. Em seguida, multiplica-se essa área pelo FR médio e pela precipitação média, obtendo-se um volume ótimo de $27,5 \mathrm{~m}^{3}$.

Tabela 3: Aplicação do método de otimização para a cidade de lbotirama-BA

\begin{tabular}{|c|c|c|c|c|c|c|c|c|c|}
\hline $\begin{array}{l}\text { Demanda } \\
\text { diária / (I) }\end{array}$ & $\begin{array}{c}F_{R} \\
\text { ótimo }\end{array}$ & $\begin{array}{c}F_{D} \\
\text { ótimo }\end{array}$ & $\begin{array}{c}\text { A } \\
\text { ótima / } \\
\left(\mathrm{m}^{2}\right)\end{array}$ & $\begin{array}{l}{ }^{1} A_{F M} / \\
\left(m^{2}\right)\end{array}$ & $\begin{array}{c}V \\
\text { ótimo / } \\
\left(\mathrm{m}^{3}\right)\end{array}$ & $\begin{array}{l}{ }^{2} V_{F M} / \\
\left(m^{3}\right)\end{array}$ & $\begin{array}{c}\text { Custo } \\
\text { Total } \\
\text { ótimo / } \\
(\mathbf{R} \$ 1000)\end{array}$ & $\begin{array}{l}{ }^{3} \text { Custo } \\
\text { Total FM / } \\
(\mathbf{R} \$ 1000)\end{array}$ & $\begin{array}{c}\text { Erro / } \\
(\%)\end{array}$ \\
\hline 60 & 0,464 & 0,757 & 40 & 39,7 & 13,4 & 13,8 & 8,87 & 8,90 & 0,37 \\
\hline 120 & 0,466 & 0,757 & 80 & 79,4 & 26,9 & 27,5 & 14,64 & 14,65 & 0,10 \\
\hline 180 & 0,464 & 0,757 & 120 & 119,1 & 40,2 & 41,3 & 19,89 & 19,90 & 0,10 \\
\hline 240 & 0,464 & 0,757 & 160 & 158,8 & 53,8 & 55,0 & 24,91 & 24,90 & $-0,01$ \\
\hline 300 & 0,514 & 0,776 & 195 & 198,4 & 72,5 & 68,8 & 29,71 & 29,74 & 0,11 \\
\hline 360 & 0,503 & 0,773 & 235 & 238,1 & 85,6 & 82,5 & 34,39 & 34,46 & 0,22 \\
\hline
\end{tabular}

1 Área de captação obtida por meio de $F_{D}$ e $F_{R}$ médios

2 Volume de armazenamento obtido por meio de $F_{D}$ e $F_{R}$ médios

${ }^{3}$ Custo total resultante do dimensionamento feito com $F_{D}$ e $F_{R}$ médios

Fonte: Os autores (2021).

Observou-se, também, a existência de uma relação linear positiva entre a demanda diária e as variáveis área e volume ótimos. O grau dessa relação foi medido por meio do coeficiente de correlação de Pearson, que atingiu $r=1,000$ para o primeiro caso e $r=0,998$ para 0 segundo. Essas correlações podem ser classificadas como perfeitas, de acordo com a categorização sugerida por Callegari-Jacques (2007).Tendo em vista ainda os valores de R-quadrado encontrados através do processo de regressão linear (Figura 4), que são aproximadamente iguais a 1, conclui-se que é possível realizar estimativas de área e volume ótimos por meio de equações que dependem apenas da demanda.

Essa conclusão tem grande importância, já que apresenta um recurso simplificado de dimensionamento ótimo do SCAC. Neste caso, não é necessário conhecer as Frações Médias de Demanda e Reservação e a precipitação anual do local, sendo preciso apenas substituir a demanda desejada em equações lineares. Para Ibotirama, são utilizadas as Equações 7 e 8. 
Figura 4: Correlação entre demanda diária, área de captação e volume do reservatório para a cidade de Ibotirama-BA

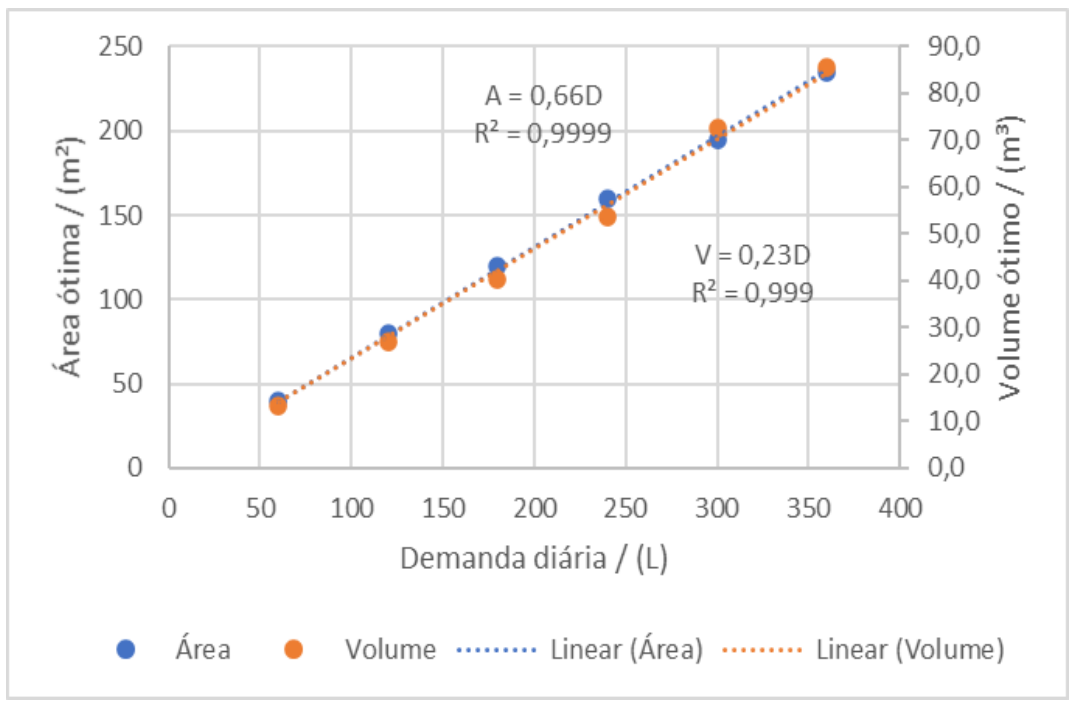

Fonte: Os autores (2021).

$A=0,66 \cdot D$

$V=0,23 \cdot \mathrm{D}$

Em que, A corresponde à área ótima $\left(\mathrm{m}^{2}\right)$; $\mathrm{V}$ representa o volume ótimo $\left(\mathrm{m}^{3}\right)$ e $\mathrm{D}$ é a demanda diária total (L). A aplicação ao caso de lbotirama para a demanda de $120 \mathrm{~L}$ seria:

$A=0,66 \cdot 120=79,2 \mathrm{~m}^{2}$

$V=0,23 \cdot 120=27,6 \mathrm{~m}^{3}$

Silva e Maia (2021), em um estudo aplicado a municípios do estado do Rio Grande do Norte, também desenvolveram equações empíricas que simplificam o processo de dimensionamento de reservatórios de água de chuva. A primeira equação fornece o volume de armazenamento, baseando-se no método de Rippl e considerando como variáveis independentes a demanda, área de captação, precipitação anual, GCP e precipitação crítica, definida como a menor pluviosidade capaz de atender à demanda mensal. A segunda determina a eficiência dos tanques, a partir do volume encontrado e das variáveis presentes na primeira expressão. Entretanto, essas equações não fornecem 0 melhor tamanho para o reservatório de água de chuva, como o mais econômico, por exemplo. Por mais que em uma dada localidade seja especificada uma demanda e eficiência de atendimento, as diferentes possibilidades de área de captação levam a volumes variados. Portanto, as Equações 7 e 8, além de possuírem apenas uma variável independente e serem mais simples de se utilizar, destacam-se pelos resultados otimizados.

A Tabela 4 apresenta um comparativo entre os métodos de obtenção dos valores de área e volume ótimos, baseando-se nos resultados do posto de lbotirama, de modo que: Custo Total ${ }_{\text {REF }}$ corresponde ao custo decorrente do uso direto do modelo comportamental, tido como referência; Custo Total ${ }_{F M}$ corresponde àquele gerado a partir dos valores médios de Fração de Demanda e de Reservação; e Custo Total $\mathbb{D}$ refere-se ao obtido pelas equações de área e volume em função da demanda. Os dois métodos alternativos mostram custos bastante similares aos valores ótimos de referência, sendo isto evidenciado por erros abaixo de $1 \%$ em todas as demandas analisadas. Qualquer uma das técnicas de dimensionamento desenvolvidas pode substituir o uso do modelo comportamental e ambas são importantes por fornecer resultados ótimos com maior praticidade. 
Tabela 4: Comparativo entre os custos totais dos métodos de otimização para a cidade de Ibotirama-BA

\begin{tabular}{|c|c|c|c|c|c|}
\hline $\begin{array}{l}\text { Demanda } \\
\text { diária / (L) }\end{array}$ & $\begin{array}{c}\text { Custo } \\
\text { Total } \\
\text { (REF } / \\
\end{array}$ & $\begin{array}{c}{ }^{2} \text { Custo } \\
\text { Total }_{\mathrm{FM}} / \\
(\mathbf{R} \$)\end{array}$ & $\begin{array}{c}{ }^{3} \mathrm{ErrO}_{\mathrm{FM}} / \\
(\%)\end{array}$ & $\begin{array}{c}{ }^{4} \text { Custo } \\
\text { Total }_{D} /(\mathbf{R} \$)\end{array}$ & $\begin{array}{c}{ }^{5} \text { Erro D / } \\
(\%)\end{array}$ \\
\hline 60 & 8870,06 & 8903,19 & 0,37 & 8903,12 & 0,37 \\
\hline 120 & 14637,33 & 14651,76 & 0,10 & 14646,61 & 0,06 \\
\hline 180 & 19885,66 & 19904,76 & 0,10 & 19893,75 & 0,04 \\
\hline 240 & 24906,58 & 24903,61 & $-0,01$ & 24886,34 & $-0,08$ \\
\hline 300 & 29708,32 & 29741,02 & 0,11 & 29717,23 & 0,03 \\
\hline 360 & 34388,40 & 34464,29 & 0,22 & 34433,80 & 0,13 \\
\hline
\end{tabular}

${ }^{1}$ Custo total real, originado pelo uso direto do modelo comportamental

${ }^{2}$ Custo total resultante do dimensionamento feito com $F_{D}$ e $F_{R}$ médios

${ }^{3}$ Erro entre os custos totais reais e os decorrentes do uso das frações médias

${ }^{4}$ Custo total resultante do dimensionamento feito com as equações lineares

${ }^{5}$ Erro entre os custos totais reais e os decorrentes do uso das equações lineares

Fonte: Os autores (2021).

\subsection{Resultados gerados para os dez municípios}

Foram calculados os valores ótimos de área e volume para todas as demandas diárias contidas no intervalo de 60 a $360 \mathrm{~L}$, bem como a eficiência de atendimento, os custos e Frações de Demanda e Reservação associadas. Além desses valores, o programa computacional também calculou FD e FR médios, assim como as novas áreas, volumes, eficiências, custos e erros. Os resultados foram exportados para uma planilha Excel, na qual foi possível aplicar a simplificação do procedimento e construir as equações de área e volume em função da demanda.

A Tabela 5 exibe os principais resultados encontrados para as dez cidades estudadas, assim como os respectivos valores de precipitação média anual e Grau de Concentração da Precipitação. Como o programa analisou um número maior de demandas em comparação com o estudo de caso, os valores de FD e FR médios exibidos nessa tabela são mais precisos. Percebe-se que cidades com GCPs diferentes, mas precipitações anuais semelhantes, como Rafael Jambeiro e Itaguaçu da Bahia, apresentam valores de FD médio bem próximos, especificamente 0,724 e 0,718 . O mesmo não acontece quando se analisa o FR médio, que varia de 0,268 a 0,596 para os respectivos municípios. Como a demanda e a precipitação se mantêm constantes para os dois casos, a pouca variação da Fração Média de Demanda não provocará mudanças significativas na área ótima, o que vai contribuir para que o crescimento da Fração Média de Reservação se torne o único fator a impactar no volume da cisterna, aumentando-o. Assim, a distribuição temporal das chuvas influencia no dimensionamento dos reservatórios, sendo que quanto mais concentrado for 0 regime pluviométrico, maior será o volume ótimo de armazenamento, conforme observado por Araújo e Cohim (2017).

Em geral, os erros associados aos custos foram muito baixos para ambos os métodos utilizados, independentemente da demanda e da cidade analisada. Todos os municípios apresentaram erro médio abaixo de 1,3\%, tanto ao se utilizar as Frações Médias de Demanda e Reservação, como ao se recorrer às equações de área e volume no processo de dimensionamento. A partir dessa verificação, foi possível validar que as duas técnicas de dimensionamento do sistema de captação e armazenamento de água pluvial fornecem valores de área e volume ótimos. Sendo assim, cada município pode ser associado a dois parâmetros fundamentais, nomeadamente $F_{D}$ e $F_{R}$ médios, e a duas equações lineares que dependem apenas da demanda diária.

Analisando as equações de cada cidade estudada, é possível notar que municípios com precipitação média anual elevada apresentam coeficientes angulares mais baixos, tanto para o cálculo da área, quanto para o do volume (Tabela 6). O mesmo não é verificado para locais com menores precipitações médias, os quais, portanto, apresentarão maiores dimensões de cobertura e reservatório. Considerando uma 
demanda diária de 120 L, a combinação ótima para a cidade de Aratuípe seria composta por $32,4 \mathrm{~m}^{2}$ de área de captação e reservatório com
8,4 $\mathrm{m}^{3}$, enquanto que em Queimadas, corresponderia a $114,0 \quad \mathrm{~m}^{2}$ e $27,6 \quad \mathrm{~m}^{3}$, respectivamente.

Tabela 5: Principais resultados das dez cidades estudadas

\begin{tabular}{ccccccc}
\hline Município & $\begin{array}{c}\text { Precipitação } \\
\text { média anual/ } \\
(\mathbf{m m})\end{array}$ & $\mathbf{G C P}$ & $\begin{array}{c}\mathbf{F}_{\mathbf{D}} \\
\text { médio }\end{array}$ & $\begin{array}{c}\mathbf{F}_{\mathbf{R}} \\
\text { médio }\end{array}$ & $\begin{array}{c}\text { 1Erro } \\
\text { médio FM / } \\
(\%)\end{array}$ & $\begin{array}{c}\text { 2Erro } \\
\text { médio } \mathbf{D} / \\
(\%)\end{array}$ \\
\hline Aratuípe & 1999,1 & 0,244 & 0,665 & 0,122 & 0,79 & 0,31 \\
Itaguaçu da Bahia & 573,8 & 0,624 & 0,718 & 0,596 & 0,48 & 0,48 \\
Angical & 949,7 & 0,604 & 0,739 & 0,406 & 0,42 & 0,42 \\
Alcobaça & 1512,5 & 0,047 & 0,640 & 0,150 & 0,70 & 0,98 \\
Miguel Calmon & 649,1 & 0,381 & 0,720 & 0,459 & 0,48 & 0,16 \\
Cândido Sales & 755,4 & 0,472 & 0,738 & 0,401 & 0,21 & 0,19 \\
Planalto & 975,9 & 0,231 & 0,687 & 0,189 & 0,45 & 0,26 \\
Ibotirama & 723,4 & 0,607 & 0,761 & 0,476 & 0,10 & 0,23 \\
Queimadas & 519,1 & 0,280 & 0,736 & 0,458 & 0,25 & 0,16 \\
Rafael Jambeiro & 615,2 & 0,195 & 0,724 & 0,268 & 1,17 & 1,28
\end{tabular}

${ }^{1}$ Erro médio entre os custos totais reais e os decorrentes do uso das frações médias

${ }^{2}$ Erro médio entre os custos totais reais e os decorrentes do uso das equações lineares

Fonte: Os autores (2021).

Tabela 6: Equações de área e volume ótimos associadas aos dez municípios estudados

\begin{tabular}{cccc}
\hline Município & $\begin{array}{c}\text { Precipitação média } \\
\text { anual / (mm) }\end{array}$ & Área & Equações \\
& 1999,1 & $A=0,27 \cdot D$ & $V=0,07 \cdot D$ \\
Aratuípe & 573,8 & $A=0,89 \cdot D$ & $V=0,30 \cdot D$ \\
Itaguaçu da Bahia & 949,7 & $A=0,51 \cdot D$ & $V=0,21 \cdot D$ \\
Angical & 1512,5 & $A=0,36 \cdot D$ & $V=0,10 \cdot D$ \\
Alcobaça & 649,1 & $A=0,78 \cdot D$ & $V=0,23 \cdot D$ \\
Miguel Calmon & 755,4 & $A=0,65 \cdot D$ & $V=0,20 \cdot D$ \\
Cândido Sales & 975,9 & $A=0,54 \cdot D$ & $V=0,10 \cdot D$ \\
Planalto & 723,4 & $A=0,66 \cdot D$ & $V=0,24 \cdot D$ \\
Ibotirama & 519,1 & $A=0,95 \cdot D$ & $V=0,23 \cdot D$ \\
Queimadas & 615,2 & $A=0,79 \cdot D$ & $V=0,16 \cdot D$ \\
Rafael Jambeiro & & &
\end{tabular}

Fonte: Os autores (2021).

\subsection{Análise de sensibilidade do custo total}

Os resultados da análise de sensibilidade para Rafael Jambeiro (Tabela 7) revelam que, entre os dois parâmetros, a área de captação corresponde àquele cuja variação de custo possui maior relevância no custo total do sistema. Para todas as demandas diárias analisadas, os valores de custo total gerados a partir do aumento no custo do telhado foram maiores do que aqueles gerados quando o aumento de custo ocorre no reservatório. Isso foi verificado tanto para os acréscimos de $25 \%$, quanto para os de $50 \%$.

Em geral, os resultados em Itaguaçu da Bahia (Tabela 8) também demonstram uma maior sensibilidade do custo total a variações no custo 
do telhado. Isso não foi percebido apenas para a solicitação hídrica diária de $60 \mathrm{~L}$, em que a diferença entre os custos totais gerados pelo aumento no custo do telhado e no custo do reservatório não foi tão expressiva. Verificou-se que a sensibilidade aumenta conforme a demanda diária cresce, principalmente para 0 acréscimo de $50 \%$ nos custos.

As equações de custo da área de captação e do reservatório influenciam o comportamento da curva de custo total e, consequentemente, a definição do ponto ótimo. Entretanto, nessa análise de sensibilidade não ficou claro um padrão de variação de área e volume ótimos em função da mudança de custos, o que se justifica pela influência dos regimes pluviométricos e do próprio comportamento dos reservatórios como resposta de rendimento ao volume demandado.

Tabela 7: Análise de sensibilidade do custo total para a cidade de Rafael Jambeiro

\begin{tabular}{ccccccc}
\hline $\begin{array}{c}\text { Demanda } \\
\text { diária (L) }\end{array}$ & $\begin{array}{c}\text { Custo Total } \\
\text { de }\end{array}$ & \multicolumn{2}{c}{$\begin{array}{c}\text { Custo Total para aumento de } \\
\text { 25\% no custo do: }\end{array}$} & \multicolumn{2}{c}{$\begin{array}{c}\text { Custo Total para aumento } \\
\text { de 50\% no custo do: }\end{array}$} \\
& referência & Telhado & Reservatório & Telhado & Reservatório \\
\hline 60 & $\mathrm{R} \$ 8.398,60$ & $\mathrm{R} \$ 9.681,00$ & $\mathrm{R} \$ 9.215,90$ & $\mathrm{R} \$ 10.860,00$ & $\mathrm{R} \$ 10.006,00$ \\
120 & $\mathrm{R} \$ 14.707,00$ & $\mathrm{R} \$ 17.071,00$ & $\mathrm{R} \$ 15.935,00$ & $\mathrm{R} \$ 19.356,00$ & $\mathrm{R} \$ 17.126,00$ \\
180 & $\mathrm{R} \$ 20.567,00$ & $\mathrm{R} \$ 23.979,00$ & $\mathrm{R} \$ 22.119,00$ & $\mathrm{R} \$ 27.186,00$ & $\mathrm{R} \$ 23.651,00$ \\
240 & $\mathrm{R} \$ 26.202,00$ & $\mathrm{R} \$ 30.533,00$ & $\mathrm{R} \$ 28.086,00$ & $\mathrm{R} \$ 34.669,00$ & $\mathrm{R} \$ 29.879,00$ \\
300 & $\mathrm{R} \$ 31.582,00$ & $\mathrm{R} \$ 36.823,00$ & $\mathrm{R} \$ 33.849,00$ & $\mathrm{R} \$ 41.952,00$ & $\mathrm{R} \$ 35.896,00$ \\
360 & $\mathrm{R} \$ 36.797,00$ & $\mathrm{R} \$ 42.987,00$ & $\mathrm{R} \$ 39.472,00$ & $\mathrm{R} \$ 49.127,00$ & $\mathrm{R} \$ 41.769,00$ \\
\hline
\end{tabular}

Fonte: Os autores (2021).

Tabela 8: Análise de sensibilidade do custo total para a cidade de Itaguaçu da Bahia

\begin{tabular}{ccccccc}
\hline $\begin{array}{c}\text { Demanda } \\
\text { diária (L) }\end{array}$ & $\begin{array}{c}\text { Custo Total } \\
\text { de }\end{array}$ & \multicolumn{2}{c}{$\begin{array}{c}\text { Custo Total para aumento de } \\
\text { 25\% no custo do: }\end{array}$} & \multicolumn{2}{c}{$\begin{array}{c}\text { Custo Total para aumento } \\
\text { de 50\% no custo do: }\end{array}$} \\
& & Telhado & Reservatório & Telhado & Reservatório \\
\hline 60 & $\mathrm{R} \$ 10.954,00$ & $\mathrm{R} \$ 12.263,00$ & $\mathrm{R} \$ 12.294,00$ & $\mathrm{R} \$ 13.546,00$ & $\mathrm{R} \$ 13.633,00$ \\
120 & $\mathrm{R} \$ 18.378,00$ & $\mathrm{R} \$ 20.826,00$ & $\mathrm{R} \$ 20.454,00$ & $\mathrm{R} \$ 23.274,00$ & $\mathrm{R} \$ 22.400,00$ \\
180 & $\mathrm{R} \$ 25.118,00$ & $\mathrm{R} \$ 28.732,00$ & $\mathrm{R} \$ 27.783,00$ & $\mathrm{R} \$ 32.346,00$ & $\mathrm{R} \$ 30.293,00$ \\
240 & $\mathrm{R} \$ 31.559,00$ & $\mathrm{R} \$ 36.338,00$ & $\mathrm{R} \$ 34.614,00$ & $\mathrm{R} \$ 41.118,00$ & $\mathrm{R} \$ 37.620,00$ \\
300 & $\mathrm{R} \$ 37.774,00$ & $\mathrm{R} \$ 43.836,00$ & $\mathrm{R} \$ 41.155,00$ & $\mathrm{R} \$ 49.899,00$ & $\mathrm{R} \$ 44.537,00$ \\
360 & $\mathrm{R} \$ 44.719,00$ & $\mathrm{R} \$ 52.413,00$ & $\mathrm{R} \$ 48.204,00$ & $\mathrm{R} \$ 60.108,00$ & $\mathrm{R} \$ 51.689,00$ \\
\hline
\end{tabular}

Fonte: Os autores (2021).

\section{CONCLUSÃO}

Esta pesquisa buscou desenvolver uma metodologia de dimensionamento otimizado de sistemas de captação e armazenamento de águas pluviais para fins domésticos, tendo como base a minimização de custos e uma eficiência de atendimento compatível com o contexto da população rural baiana. Foram consideradas dez cidades situadas em regiões específicas de homogeneidade pluviométrica, a fim de retratar a alta variabilidade espacial e temporal das precipitações do estado da Bahia.

Inicialmente, verificou-se que, a partir de dois parâmetros adimensionais (Fração Média de Demanda e Fração Média de Reservação), é possível determinar as dimensões ideais para a 
cobertura e o reservatório do sistema. Em seguida, notou-se a existência de uma forte relação positiva entre a demanda diária e as variáveis área e volume ótimos, o que proporcionou a estimativa desses valores por meio de equações lineares que dependem apenas da demanda.

As diferenças percentuais entre os custos totais gerados pela aplicação das técnicas de dimensionamento desenvolvidas e pelas combinações ótimas de referência foram, em geral, muito baixas, independentemente da solicitação hídrica e da cidade analisada. $O$ erro médio associado aos custos totais se manteve abaixo de $1,3 \%$ para todos os municípios analisados, tanto ao se utilizar as Frações Médias de Demanda e Reservação, quanto ao se recorrer às equações de área e volume.

Percebeu-se que a distribuição temporal das chuvas influencia no dimensionamento dos reservatórios, sendo que quanto mais concentrado for o regime, maior será o volume ótimo de armazenamento. Em relação à análise de sensibilidade do custo total, foi verificada uma maior sensibilidade à variação do custo do telhado para as cidades de Rafael Jambeiro e Itaguaçu da Bahia, principalmente para demandas mais altas e incrementos de $50 \%$ nos custos. Entretanto, não ficou claro um padrão de variação de área e volume ótimos em função da mudança de custo dos componentes do SCAC, o que pode ser explicado pela influência dos padrões de chuva e do próprio comportamento dos reservatórios para atender às demandas especificadas.

Ambos os métodos apresentados simplificam o processo de dimensionamento do SCAC, já que dispensam o uso das equações do modelo comportamental, da série de dados pluviométricos e das diferentes combinações de área e volume. Ao optar por utilizar as Frações Médias de Demanda e Reservação, o usuário necessitará desses dois parâmetros, do valor de precipitação anual média e da demanda hídrica. Caso recorra às equações de área e volume, precisará informar somente a demanda.

Ressalta-se a importância deste estudo visto que ainda existem poucos trabalhos na literatura que realizam o dimensionamento ótimo do sistema de aproveitamento de água de chuva em ambiente rural. Os autores recomendam a ampliação do número de municípios em trabalhos futuros, com 0 intuito de fornecer uma representação mais realista das condições de cada local e permitir que residentes de qualquer município da Bahia consigam realizar o dimensionamento com maior precisão.

\section{FINANCIAMENTO DA PESQUISA}

Esta pesquisa contou com 0 incentivo do Conselho Nacional de Desenvolvimento Científico e Tecnológico (CNPq) e da Fundação de Amparo à Pesquisa do Estado da Bahia (FAPESB), os quais concederam, respectivamente, bolsas de Iniciação Científica e Mestrado.

\section{REFERÊNCIAS}

ANA - AGÊNCIA NACIONAL DE ÁGUA. HIDROWEB. Disponível em:

http://www.snirh.gov.br/hidroweb/serieshistoricas. Acesso em: 1‥ mar. 2021.

ANDRADE NETO, C. O. Aproveitamento imediato da água de chuva. GESTA: Revista Eletrônica de Gestão e Tecnologias Ambientais, v. 1, n. 1, p. $67-$ 80, 2013. doi:

http://dx.doi.org/10.17565/gesta.v1i1.7106. Disponível em:

https://periodicos.ufba.br/index.php/gesta/article/view/7 106. Acesso em: 03 mar. 2021.

ARAUJO, J. F.; COHIM, E. Determinação do tamanho ótimo dos reservatórios de água pluvial em Araci na Bahia. In: SIMPÓSIO DE RECURSOS HÍDRICOS DO NORDESTE, 13., 2016, Aracaju. Anais... Aracajú-SE: ABRhidro, 2016.

; COHIM, E. The interference of rainfall distribution in size of rain water tanks in Bahia. Journal of Engineering and Technology for Industrial Applications, [S. L.], v. 3, n. 10, p. 190-193, 2017. doi: 10.5935/2447-0228.20170050. Disponível em: https://www.researchgate.net/publication/317574473_T HE_INTERFERENCE_OF_RAINFALL_DISTRIBUTION IIN_SIZE_OF_RAIN_WATER_TANKS_IN_BAHIA. Acesso em: 02 mar. 2021.

ARAÚJO, S. M. S de. A região semiárida do Nordeste do Brasil: questões ambientais e possibilidades de uso sustentável dos recursos. Rios Eletrônica- Revista Científica da FASETE, [S. L.], v. 5, n. 5, p. 88-98, 2011.

ASA - ARTICULAÇÃO NO SEMIÁRIDO BRASILEIRO. É no Semiárido que a vida 
pulsa! Disponível em: http://asabrasil.org.br/semiarido. Acesso em: 05 jan. 2021a.

. Programa 1 milhão de cisternas. Disponível em: http://www.asabrasil.org.br/acoes/p1mc. Acesso em: 05 jan. 2021b.

BRASIL. Lei n 9.433/1997. Institui a Política Nacional de Recursos Hídricos, cria o Sistema Nacional de Gerenciamento de Recursos Hídricos, regulamenta o inciso XIX do art. 21 da Constituição Federal, e altera o art. $1^{\circ}$ da Lei $n^{\circ} 8.001$, de 13 de março de 1990, que modificou a Lei no 7.990, de 28 de dezembro de 1989 . Diário Oficial da União, Brasília, DF, 09 jan. 1997. Disponível em:

http://www.planalto.gov.br/ccivil_03/leis/19433.htm. Acesso em: 15 jan. 2021.

Ministério do Desenvolvimento Agrário. Secretaria de Desenvolvimento Territorial. Plano Territorial de Desenvolvimento Sustentável do Velho Chico. Bahia: SDT/MDA, 2010. Disponível em: http://sit.mda.gov.br/download/ptdrs/ptdrs_qua_territorio 015.pdf. Acesso em: 15 jan. 2021.

. Ministério da Integração Nacional. Conselho Deliberativo da Superintendência do Desenvolvimento do Nordeste. Resolução no 115, de 23 de novembro de 2017. Aprova a Proposição no 113/2017, que acrescenta municípios à relação aprovada pela Resolução CONDEL no 107, de 27 de julho de 2017. Diário Oficial da União, Brasília, DF, 05 dez. 2017. Seção 1, p.32-34. Disponível em: https://www.in.gov.br/materia//asset_publisher/Kujrw0TZC2Mb/content/id/739568/do1 -2017-12-05-resolucao-n-115-de-23-de-novembro-de2017-739564. Acesso em: 03 mar. 2021. . Ministério do Meio Ambiente. Secretaria dos Recursos Hídricos. Plano Nacional dos Recursos Hídricos. Brasília: SRH/MMA, 2006. Disponível em: https://arquivos.ana.gov.br/institucional/sge/CEDOC/Ca talogo/2006/PNRHSintese.pdf. Acesso em: 05 mar. 2021.

CALLEGARI-JACQUES, S. M. Bioestatística: princípios e aplicações. Porto Alegre: Artmed, 2007.

CAMPISANO, A.; MODICA, C. Optimal sizing of storage tanks for domestic rainwater harvesting in Sicily. Resources, Conservation and Recycling, [S.L.], v. 63, p. 9-16, 2012. doi: 10.1016/j.resconrec.2012.03.007. Disponível em: https://www.researchgate.net/publication/235982214_O ptimal_sizing_of_storage_tanks_for_domestic_rainwate r_harvesting_in_Sicily. Acesso em: 02 mar. 2021.

COHIM, E.; ORRICO, S. R. M. A confiabilidade do volume das cisternas da zona rural para reservar água de chuva. GESTA: Revista Eletrônica de Gestão e
Tecnologias Ambientais, [S. L.], v. D, p. 91-99, 2015. doi: http://dx.doi.org/10.17565/gesta.v3i2.13975. Disponível em:

https://periodicos.ufba.br/index.php/gesta/article/view/1 3975. Acesso em: 06 mar. 2021.

COSTA, P. R.; SILVEIRA, A. L. R. da. Urban drainage and the impacts arising out of the urbanization process in the corrego Bowl Mingau, Goiânia, GO. Revista Eletrônica de Educação da Faculdade Araguaia, [S. L.], v. 11, n. 11, p. 76-100, 2017.

DINIZ, A. F. Estudo da variabilidade da pluviosidade (1994-2010) no município de Feira de Santana (Bahia) e seus reflexos na agricultura de sequeiros: o caso do milho. 2012. 114 f. Dissertação (Mestrado em Geografia) - Instituto de Geociências. Universidade Federal da Bahia, Salvador, 2012. Disponível em: https://repositorio.ufba.br/ri/bitstream/ri/19786/1/Aline\% 20Diniz.pdf. Acesso em: 15 jan. 2021.

FEWKES, A. Modelling the performance of rainwater collection systems: towards a generalised approach. Urban Water, Nottingham, v. 1, n. 4, p. 323-333, 2000. doi: 10.1016/S1462-0758(00)00026-1. Disponível em: https://www.researchgate.net/publication/223629806_M odelling_the_Performance_of_Rainwater_Collection_Sy stems_Towards_A_Generalised_Approach. Acesso em: 13 mar. 2021.

GHISI, E. Parameters influencing the sizing of rainwater tanks for use in Houses. Water Resources

Management, [S. L.], v. 24, n. 10, p. 2381-2403, 2010. doi:

http://dx.doi.org/10.1007/s11269-009-9557-4.

Disponível em:

https://labeee.ufsc.br/index.php/node/333. Acesso em: 12 mar. 2021.

GIFFONI, V. V.; COHIM, E. Otimização de volumes de reservatórios de água de chuva para uso pecuário. GESTA: Revista Eletrônica de Gestão e Tecnologias Ambientais, v. 7, n. 2, p. 151-159, 2019. doi: http://dx.doi.org/10.9771/gesta.v7i2.30775.

Disponível em:

https://periodicos.ufba.br/index.php/gesta/article/view/3 0775. Acesso em: 06 jan. 2021.

GURUNG, T. R.; SHARMA, A.; UMAPATHI, $S$. Economics of scale analysis of communal rainwater tanks. Brisbane, Qld, Australia: Urban Water Security Research Alliance, 2012. Disponível em: http://hdl.handle.net/102.100.100/100616?index=. Acesso em: 12 mar. 2021.

IBGE - INSTITUTO BRASILEIRO DE GEOGRAFIA E ESTATÍSTICA. Censo demográfico 2010. 2010. Disponível 
https://www.ibge.gov.br/estatisticas/downloadsestatisticas.html. Acesso em: 06 jan. 2021.

Cidades e Estados. 2020. Disponível em: https://www.ibge.gov.br/cidades-e-estados/ba.html. Acesso em: 05 jan. 2021.

Semiárido Brasileiro. 2017. Disponível em: https://www.ibge.gov.br/geociencias/cartas-emapas/mapas-regionais/15974-semiaridobrasileiro.html?=\&t=sobre. Acesso em: 05 jan. 2021.

IPEA - INSTITUTO DE PESQUISA ECONÔMICA APLICADA. Taxa de câmbio comercial para compra. 2021. Disponível em:

http://www.ipeadata.gov.br/ExibeSerie. aspx?serid=385 90\&module $=$ M. Acesso em: 20 jun. 2021.

LANI, N. H. M.; SYAFIUDDIN, A.; YUSOP,Z.; ADAM, U.B.; AMIN, M.Z.B.M. Performance of small and large scales rainwater harvesting systems in commercial buildings under different reliability and future water tariff scenarios. Science of the Total Environment, v. 636, p. 1171-1179, 2018. doi:

https://doi.org/10.1016/j.scitotenv.2018.04.41.

Disponível em:

https://www.sciencedirect.com/science/article/abs/pii/S0 048969718316176?via\%3Dihub. Acesso em: 03 mar. 2021.

LEMOS, J. J. S. Vulnerabilidades induzidas no Semiárido Brasileiro. Desenvolvimento Regional em Debate, v. 10, p. 245-268, 2020. doi 10.24302/drd.v10i0.2728. Disponível em: http://www.periodicos.unc.br/index.php/drd/article/view/ 2728. Acesso em: 23 mar. 2021.

LI, X.; JIANG, F.; LI, L.; WANG, G. Spatial and temporal variability of precipitation concentration index, concentration degree and concentration period in Xinjiang, China. International Journal of Climatology, [S.L.], v. 31, n. 11, p. 1679-1693, sep. 2011. doi: https://doi.org/10.1002/joc.2181. Acesso em: 17 fev. 2021.

MORAIS, G. F. O. Cisternas domiciliares: qualidade da água para consumo humano em comunidades rurais do semiárido Sergipano. 2016. 86 f. Dissertação (Mestrado em Desenvolvimento e Meio Ambiente) Universidade Federal da Paraíba, João Pessoa, 2016. Disponível em:

https://repositorio.ufpb.br/jspui/bitstream/tede/9144/2/ar quivototal.pdf. Acesso em: 23 fev. 2021.

ORSE - SISTEMA DE ORÇAMENTO DE OBRAS DE SERGIPE. Disponível em:

https://www.cehop.se.gov.br/orse/. Acesso em: $11 \mathrm{fev}$. 2021.
PALA, G. K.; PATHIVADA, A. P.; VELUGOTI, S. J. H.; YERRAMSETTI, C.; VEERANKI, S. Rainwater harvesting: A review on conservation, creation \& costeffectiveness. Materials Today: Proceedings, 2021.doi: 10.1016/j.matpr.2020.11.593. Disponível em: https://www.researchgate.net/publication/348902597_R ainwater_harvesting_-

A_review_on_conservation_creation_costeffectiveness. Acesso em: 18 fev. 2021.

RUEDIGER, M. A. (Coord.). Análise da efetividade do Água Para Todos: avaliação de mérito quanto à eficácia, à eficiência e à sustentabilidade. Rio de Janeiro: FGV DAPP, 2018.

SANTOS, A. A. B.; VILAS BOAS, L. D. S.; TOFANELI, L. A.; ANDRADE FILHO, M.; NEVES, P. R. F.; OLIVEIRA, T. D. (Org.). Atlas eólico Bahia. Salvador: SECTI - SEINFRA - CIMATEC/SENAI, 2013.

SANTOS, A. C.; CEBALLOS, B. S. O.; SOUSA, C. M. Políticas públicas de água e participação no semiárido: limites e tensões no P1MC. Revista Eletrônica de Gestão e Tecnologias Ambientais, v. 1, n. 1, p. 145161, 2013. doi: 10.17565/gesta.v111.8279. Disponível em:

https://www.researchgate.net/publication/294734242_P OLITICAS_PUBLICAS_DE_AGUA_E_PARTICIPACAO _NO_SEMIARIDO_LIMITES_E_TENSOES_NO_P1MC . Acesso em: 25 fev. 2021.

SANTOS, J.; MEDEIROS, C. M. de.; ANGOLA, C. de. Cisterna telhadão: inovações para a convivência com o semiárido. Recife: Centro Sabiá, 2013.

SEMAAN, M.; DAY, S. D.; GARVIN, M.; RAMAKRISHNAN, N.; PEARCE, A. Optimal sizing of rainwater harvesting systems for domestic water usages: a systematic literature review. Resources, Conservation \& Recycling: $\mathbf{X}$, [S.L.], v. 6, p. 100033100055, 2020. doi: https://doi.org/10.3390/w13040573. Disponível em:

https://www.sciencedirect.com/science/article/pii/S2590 289X20300049\#: :text=Londra\%20et\%20al.,total\%20w ater\%20demands\%20for\%20households.\&text=The\%2 0authors\%20track\%20how\%20increasing,as\%20well\% 20as\%20rainfall\%20runoff. Acesso em: 23 mar. 2021.

SILVA, M.M.M.A.; MAIA, A.G. SILVA. Equation for rainwater tank efficiency: Considering demand, roof area, tank size and pluvial regime. Environmental Challenges, v. 3, 2021.doi:

https://doi.org/10.1016/j.envc.2021.100044. Disponível em:

https://www.sciencedirect.com/science/article/pii/S2667 010021000238?via\%3Dihub. Acesso em: 21 fev. 2021.

SIMÕES, Y. S.; COHIM, E.; ARAÚJO, H. A. Rainfall zoning of Bahia State, Brazil: an update proposal. 
Revista Ambiente e Água: na Interdisciplinary Journal of Applied Sciences, Taubaté, v. 13, n. 1, 2018. doi: https://doi.org/10.4136/ambi-agua.2171. Disponível em:

https://www.scielo.br/j/ambiagua/a/nTv4gy8P3FgWY4Q

TNkzYxzD/?lang=en. Acesso em: 12 jan. 2021.

SINAPI -SISTEMA NACIONAL DE PESQUISA DE CUSTOS E ÍNDICES DA CONSTRUÇÃO CIVIL.

Disponível em: http://goo.gl/ttgltv. Acesso em: 12 fev. 2021.

SNIS - SISTEMA NACIONAL DE INFORMAÇÕES SOBRE SANEAMENTO. Mapa de Indicadores de Água. 2018. Disponível em: http://appsnis.mdr.gov.br/indicadores/web/agua_esgoto /mapa-agua. Acesso em: 09 nov. 2020.

WHO - WORLD HEALTH

ORGANIZATION. Guidelines for Drinking-water Quality. Genebra: WHO, 2011. Disponível em: http://www.iasaude.pt/attachments/article/660/WHO_Gu idelines\%20for\%20drinking-water\%20quality.pdf. Acesso em: 23 fev. 2021.

WWAP - WORLD WATER ASSESSMENT PROGRAMME. The United Nations World Water Development Report 3: water in a changing world. [S.L]: Unesco, 2009. 